Terbit online pada laman web jurnal : http://jurnal.iaii.or.id

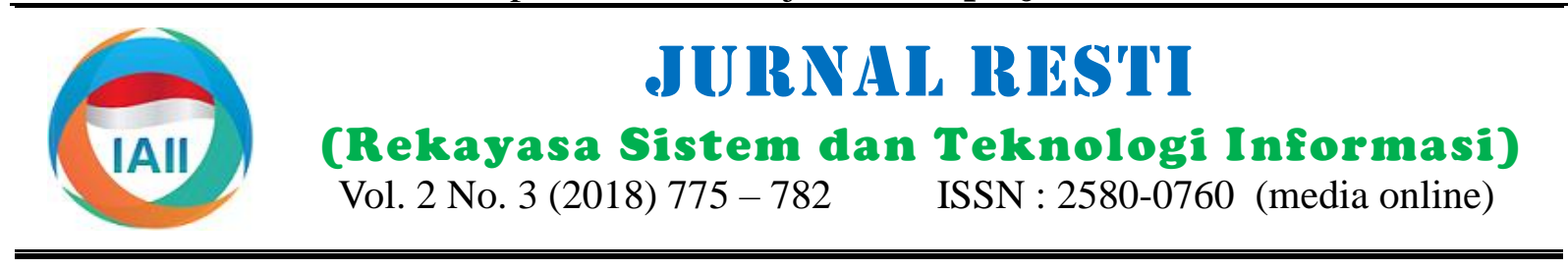

\title{
Aplikasi Info Pariwisata Kabupaten Solok Selatan Berbasis Android
}

\author{
Vivi Hasti Mayanti ${ }^{a}$, Hidra Amnur ${ }^{\text {b }}$, Humaira ${ }^{c}$, Dwiny Meidelfi ${ }^{\mathrm{d}}$ \\ a Jurusan Teknologi Informasi, Politeknik Negeri Padang, vivihastimayanti4@ gmail.com \\ b Jurusan Teknologi Informasi, Politeknik Negeri Padang, hidraamnur@ gmail.com \\ c Jurusan Teknologi Informasi, Politeknik Negeri Padang, mira.humaira@gmail.com \\ d Jurusan Teknologi Informasi, Politeknik Negeri Padang, dwiny9586@gmail.com
}

\begin{abstract}
Solok Selatan Regency is a Regency in the eastern part of the province of West Sumatra. In the County many interesting attractions to visit. As nature tourism, cultural tourism, historical tourism, culinary tourism, and lodging. There has been no use of the android technology to publish existing tourism in Solok Selatan Regency, so information on tourism objects do not meet the attraction of tourists. Tourism android-based applications are used to facilitate tourists in exposing and searching for tourism information in Solok Selatan District. This application can be used as a medium of information at once media Solok Selatan District tourism promotion. This application using GPS on Smartphones to find out the location of the user application and instructions the way to tourist sites through the Google Map. There is a menu to share sights form images to a variety of social media or tools provided on the smartphone, as well as the rating menu to perform the assessment of the tourism objects in the form of the input value rating.
\end{abstract}

Keywords: Solok Selatan, tourism, smartphone, android, GPS, google map, share, rating

\begin{abstract}
Abstrak
Kabupaten Solok Selatan adalah kabupaten yang terletak di bagian timur Provinsi Sumatera Barat. Di Kabupaten ini banyak tempat wisata yang menarik untuk dikunjungi. Seperti wisata alam, wisata budaya, wisata sejarah, wisata kuliner, dan penginapan. Belum ada penggunaan teknologi android untuk mempublikasikan pariwisata yang ada di Kabupaten Solok Selatan, sehingga informasi mengenai objek wisata belum memenuhi daya tarik wisatawan. Aplikasi Pariwisata berbasis android digunakan untuk mempermudah wisatawan dalam memperkenalkan maupun mencari informasi pariwisata di Kabupaten Solok Selatan. Sehingga aplikasi ini dapat dijadikan sebagai media informasi sekaligus media promosi pariwisata Kabupaten Solok Selatan. Aplikasi ini menggunakan GPS pada smartphone untuk mengetahui lokasi pengguna aplikasi dan petunjuk jalan menuju lokasi wisata melalui Google Map. Selain itu terdapat menu untuk share objek wisata berupa gambar ke berbagai media sosial atau tools yang disediakan pada smartphone, serta menu rating untuk melakukan penilaian terhadap objek wisata berupa inputan nilai rating.
\end{abstract}

Kata kunci: Solok Selatan, pariwisata, smartphone, android, GPS, google map, share, rating

(C) 2018 Jurnal RESTI

\section{Pendahuluan}

Solok Selatan merupakan Kabupaten dengan sejuta pesona alam yang indah dan memukau. Keindahan alam terkhusus di dunia pariwisata belum sepenuhnya terekspos menjadi sebuah komoditi yang mampu mendongkrak perekonomian masyarakat sekitar. Beberapa wahana alam yang dapat dinikmati dengan sensasi estetika yang tinggi, diantaranya adalah kebun teh Solok Selatan dengan panorama Gunung Kerinci yang memukau, Malanca (waterboom alam), Goa Batu Kapal, Puncak BRJ, Air Terjun Tangsi Empat dan Pemandian Air Panas Sapan Maluluang.
Potensi Objek wisata di Kabupaten Solok Selatan saat ini masih berupa katalog pariwisata. Untuk itu, pariwisata sekarang perlu bergerak kearah yang lebih maju dengan mengedepankan teknologi sebagai wahana promosi, salah satunya adalah aplikasi pariwisata berbasis android.

Pada jurnal ini terdapat penggunaan dan pemanfaatan teknologi android untuk memperkenalkan pariwisata Kabupaten Solok Selatan, mulai dari merancang sampai dengan membuat aplikasi pariwisata yang dapat mempublikasikan serta memberikan informasi mengenai objek wisata yang ada di Kabupaten Solok Selatan. Aplikasi dapat menampilkan peta lokasi 
wisata, berbagai ke media sosial/aplikasi lainnya, (platform-neutral) dan tidak terikat akan bahasa memberikan rating (penilaian) di setiap objek wisata. pemrograman yang digunakan

\section{Tinjauan Pustaka}

Dalam Undang-undang Republik Indonesia nomor 10 a. Analisis kebutuhan

tahun 2009 tentang kepariwisataan. Wisata merupakan Proses pengumpulan kebutuhan dilakukan pada tahap kegiatan perjalanan yang dilakukan oleh seseorang atau ini yaitu dengan wawancara ke narasumber yang kelompok orang dengan mengunjungi tempat tertentu berada di solok selatan dan lokasi wisata, dan dinas untuk suatu tujuan dalam jangka waktu sementara. pariwisata sehingga dapat membantu dalam Sedangkan Wisatawan adalah orang yang melakukan melengkapi data-data yang diperlukan. wisata.

Kegiatan kepariwisataan ini dibuat kedalam suatu aplikasi. Menurut Kamus Besar Bahasa Indonesia, aplikasi adalah penerapan dari rancang system untuk mengolah data yang menggunakan aturan atau ketentuan Bahasa pemrograman tertentu. Bahasa Pemograman yang digunakan yaitu Bahasa pemograman untuk system operasi android dengan database MySQL, dan webservice

\section{b. Desain program}

Desain program adalah proses perancangan sistem yang berupa masukan, proses, dan keluaran dari aplikasi, serta perancangan antar muka dari aplikasi. yang meliputi tampilan splashscreen, menu utama apikasi, dan menu user untuk upload wisata, menu tentang aplikasi, menu tentang Solok Selatan, menu feedback, dan menu keluar aplikasi. Desain program menggunakan UML yang terdiri dari use case, class Android adalah sistem operasi untuk telepon seluler diagram, sequence diagram.

smartphone berbasis linux sebagai kernelnya. Android menyediakan platform terbuka (open source) bagi para c. Pembuatan kode program pengembang untuk menciptakan aplikasi mereka Pembuatan kode program merupakan penerjemahan sendiri. Bahasa pemrograman yang sering digunakan desain sistem kedalam bahasa pemograman. Pada untuk mengembangkan aplikasi Android adalah Java. tahapan ini merupakan tahapan nyata pada pembuatan Namun ada beberapa bahasa lainnya yang dapat aplikasi sesuai dengan desain yang ada. digunakan, seperti C++, dan Go. Pada IO 2017, Google

juga meresmikan penggunaan Kotlin sebagai tambahan d. Pengujian program

Bahasa resmi. Masing-masing versi android dirilis Tahapan ini merupakan tahap akhir dari pembuatan sesuai dengan urutan alphabet, yakni Apple Pie (Beta), sebuah sistem dengan cara menjalankan aplikasi Banana Bread (1.0), Cupcake (1.5), Donut (1.6), sehingga dapat dilihat kesalahan program yang dibuat. Éclair(2.0-2.1), Froyo (2.2-2.2.3), Gingerbread (2.3- Pengujian program ini melalui ponsel berbasis android. 2.3.7), Honeycomb (3.0-3.2.6), Ice Cream Sandwich

(4.0-4.0.4), Jelly Bean (4.1-4.3), Kitkat (4.4+), Lollipop 4. Hasil dan Pembahasan

(5.0) dan Marhsmallow (6.0), Nougat (7.1-7.1.2), Oreo $(8.1)$

MySQL dapat digunakan untuk membuat dan mengola Perancangan

database beserta isinya. Pengguna dapat memanfaatkan Berikut struktur aplikasi pariwisata yang dirancang MYSQL untuk menambahkan, mengubah dan pada Gambar 1 Client android mengakses data ke menghapus data yang berada dalam database. MySQL database. Data diakses melalui web service. Web merupakan system manajemen database yang bersifat service akan mengirimkan data ke database.

relational. Artinya data-data yang dikelola dalam database akan diletakkan pada beberapa tabel yang terpisah sehingga manipulasi data akan menjadi jauh lebih cepat.

Web service adalah sekumpulan application logic beserta objek-objek dan metode-motode yang dimilikinya, yang terletak disuatu server yang terhubung ke internet sehingga dapat diakses menggunakan protocol HTTP dan SOAP (Simple Object Access Protocol). Tujuan dari teknologi ini adalah untuk memudahkan beberapa aplikasi komponennya untuk saling terhubung dengan aplikasi lain dalam sebuah organisasi maupun diluar organisasi menggunakan standar yang tidak terikat platform

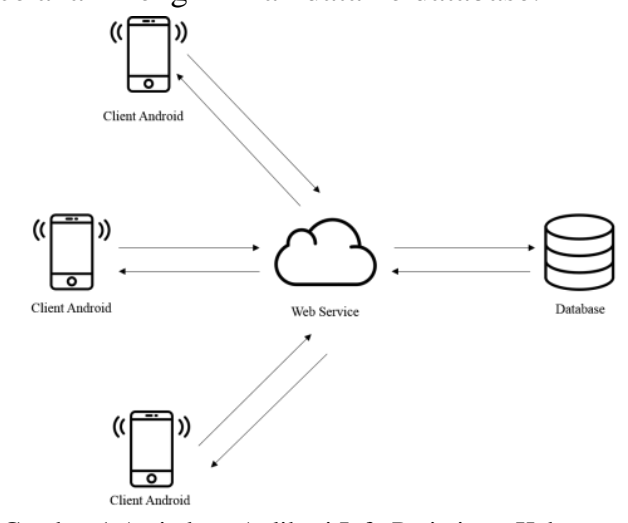

Gambar 1 Arsitektur Aplikasi Info Pariwisata Kabupaten Solok Selatan

Jurnal RESTI (Rekayasa Sistem dan Teknologi Informasi) Vol . 2 No. 3 (2018) 775 - 782 
Database menerima dan memproses data tersebut yang android yang diuji. Aplikasi ini diuji pada smartphone akan diteruskan kembali ke web service. Maka web android dengan spesifikasi sebagai berikut:

service akan mengolah data tersebut sehingga menghasilkan informasi yang akan diterima oleh client android.

\section{Struktur Men $u$}

Rancangan Struktur Menu Aplikasi

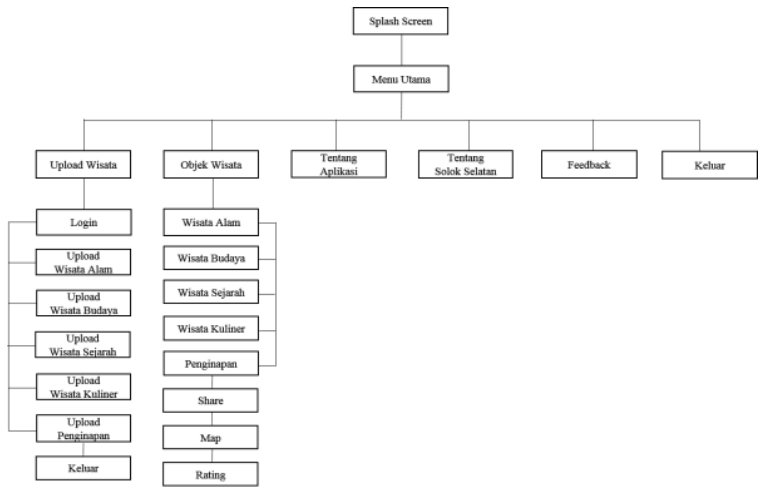

Gambar 2 Rancangan Struktur Menu Aplikasi

Dari struktur menu aplikasi pada Gambar 2 terdapat enam pilihan menu yaitu menu upload wisata, objek wisata, tentang aplikasi, tentang solok selatan, feetback dan keluar aplikasi.

Pada menu upload wisata, pengguna aplikasi dapat menambahkan objek wisata yang ada atapun wisata yang belum dijangkau wisatawan. Ada beberapa menu yaitu menu upload wisata alam, upload wisata budaya, upload sejarah, upload wisata kuliner dan upload hotel/penginapan. Sedangkan pada menu objek wisata yaitu menampilkan informasi tentang wisata yang sudah diiinputkan serta menampilkan lokasi wisata pada marker google map, menampilkan rating dan share objek wisata ke berbagai aplikasi lainnya.

\section{Hasil}

\section{Clean Program}

Clean program digunakan untuk melakukan pembersihan dan re-build terhadap program yang telah dibuat agar bisa dijalankan pada emulator/Smartphone android yang ada.

\section{Mengubah project menjadi apk}

Run projek agar projek diproses pada emulator untuk dijalankan dan file apk akan otomatis dibuat. Setelah aplikasi di run, file apk akan keluar di folder apk pada projek.

\section{Install Aplikasi}

Setelah melakukan proses run program, aplikasi yang telah dibuat dijalankaan pada emulator / smartphone android yang ada. Setelah dijalankan, aplikasi tersebut akan langsung terinstal pada emulator/smartphone
Nama smartphone : Samsung Galaxy J2 Prime, Sistem Operasi: Android API level 23 versi 6.0.1 (Marshmallow). Memory RAM: 1,5 GB. Layar: 5.0 inch.

\section{Register dan Login pada Aplikasi untuk Upload Wisata}

User dapat meng-upload objek wisata yang ada di Kabupaten Solok Selatan. Sebelum upload wisata pastikan koneksi internet pada smartphone. Jika tidak ada koneksi internet maka akan mucul pesan no internet connection seperti pada Gambar 3.

Untuk upload objek wisata, maka user harus melakukan login untuk masuk ke menu utama upload wisata. Jika belum punya akun maka harus melakukan register sebelum login dengan mengisi data seperti yang terlihat pada gambar 4. User akan menunggu proses data yang akan dihubungkan ke web service dan database seperti yang terdapat pada gambar 5 .

Jika register berhasil maka akan muncul pesan seperti yang terdapat pada gambar 6. Sebaliknya apabila pada saat register dengan menggunakan email yang sama, maka register gagal seperti pada gambar 8 .

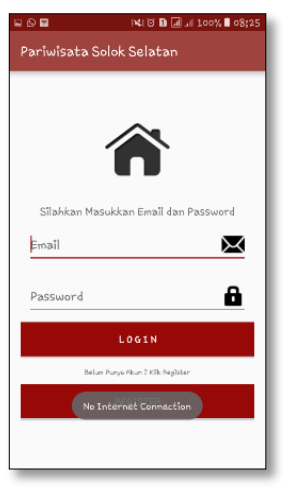

Gambar 3 Tampilan Pesan No Internet Connection

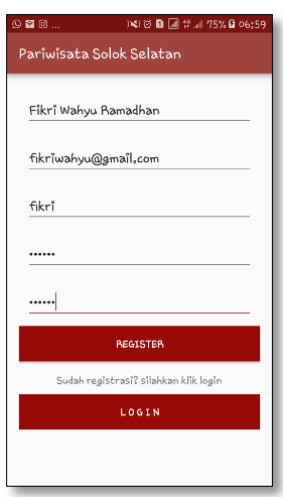

Gambar 4 Proses Pengisian Data Register 


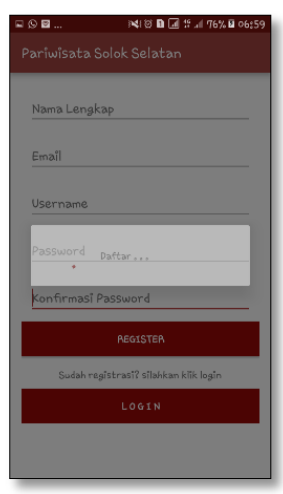

Gambar 5 Menghubungkan Data Register ke Database

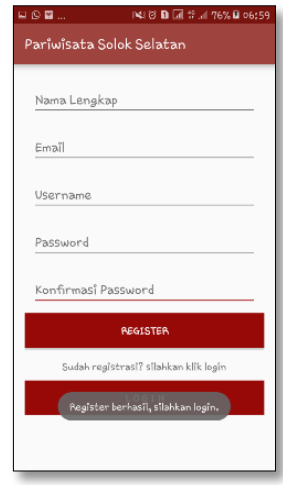

Gambar 6 Tampilan Pesan Register Berhasil

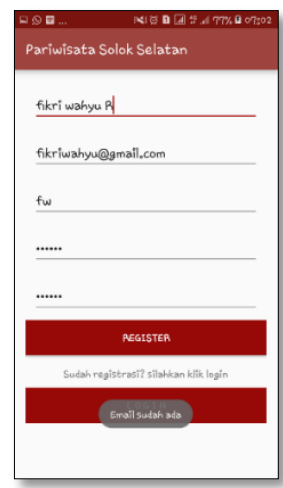

Gambar 7 Tampilan Pesan Register gagal
Apabila email atau password salah dalam proses penginputan maka akan muncul pesan seperti pada gambar 9. Tapi apabila benar dalam proses penginputan maka akan muncul tampilan ke menu utama upload wisata seperti yang terdapat pada gambar 10 .

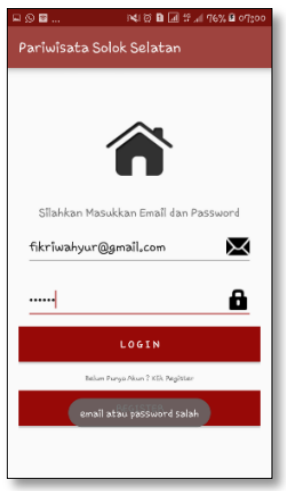

Gambar 9 Tampilan Pesan Salah Penginputan Email atau Password

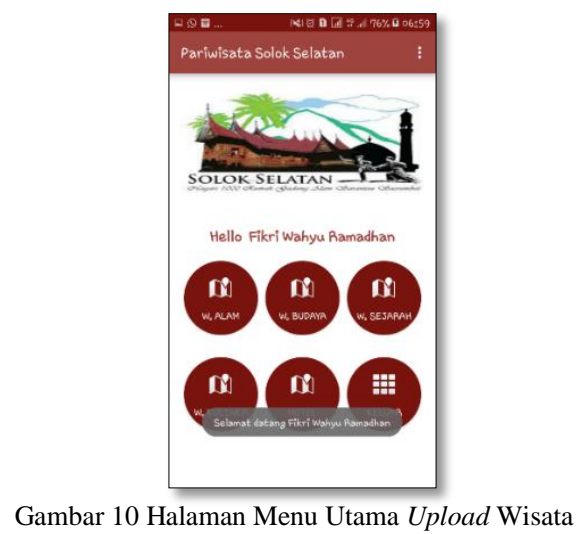

\section{Upload wisata}

Setelah login maka user dapat menginputkan/upload objek wisata yang ada di Kabupaten Solok Selatan. Misalnya upload wisata alam seperti yang terlihat pada gambar 11 Ketika user selesai menginputkan data objek wisata, maka akan muncul pesan data berhasil disimpan dan terlihat pada list wisata. Tampilan tersebut terdapat

Jika register berhasil, user dapat melakukan proses pada gambar 12 login dengan menginputkan email dan password.
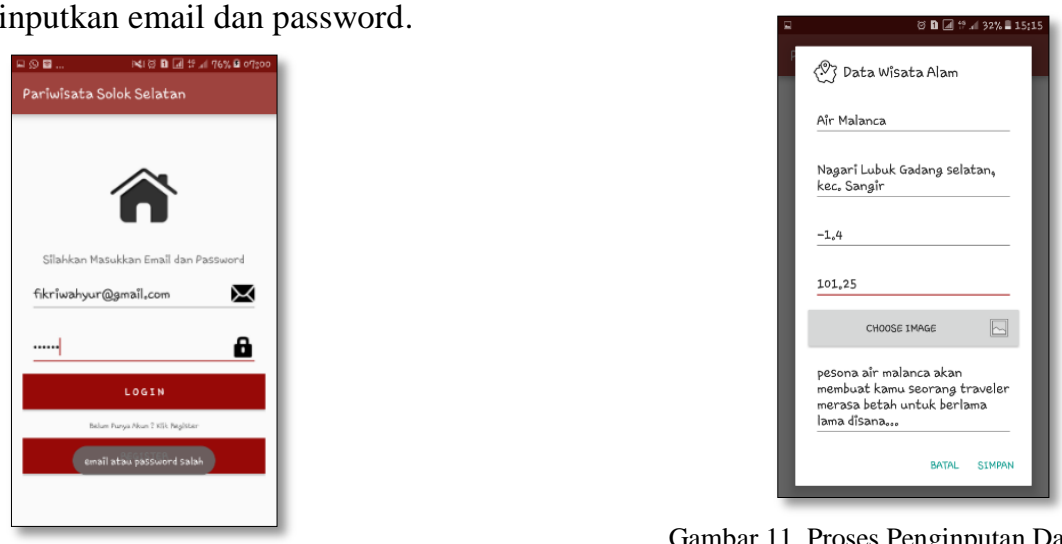

Gambar 11. Proses Penginputan Data Wisata 


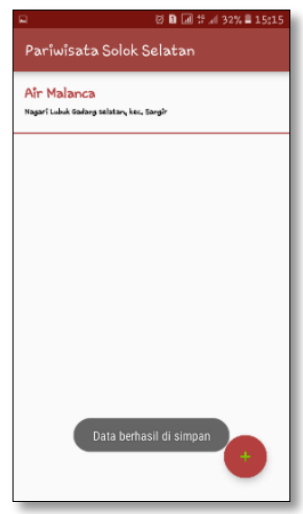

Gambar 12 Tampilan Pesan Data Berhasil Disimpan

\section{Edit dan Delete Wisata}

Wisata yang sudah di upload dapat dilakukan proses edit atau delete objek wisata tersebut, dengan klik tahan pada salah satu list objek wisata maka akan muncul pilihan edit atau delete seperti yang terdapat pada gambar 13 Proses edit data wisata terdapat pada gambar 14 Setelah proses edit maka akan muncul pesan data berhasil di update seperti yang terdapat pada gambar 15

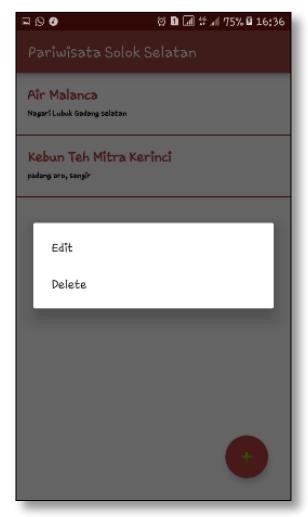

Gambar 13 Pilihan Menu Edit dan Delete Objek Wisata

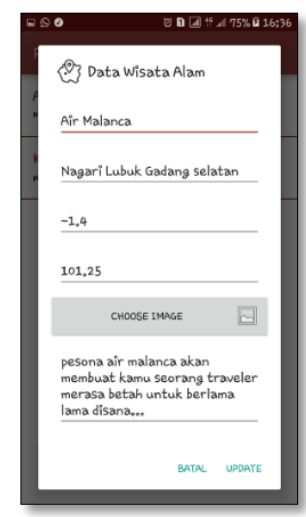

Gambar 14 Proses Edit Data Objek Wisata

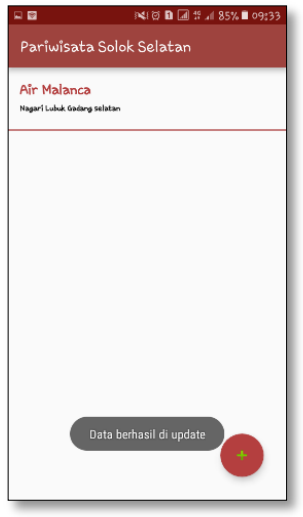

Gambar 15 Tampilan Pesan Data berhasil di Update

Tampilan pesan setelah objek wisata dihapus terdapat pada gambar 16

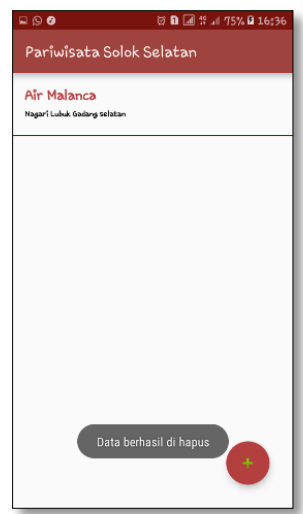

Gambar 16 Tampilan Pesan Penghapusan Data Objek Wisata

\section{Menu Share Objek Wisata}

User dapat share objek wisata yang berupa gambar ke berbagai aplikasi lainnya. Misalnya share melalui aplikasi whatsapp, share melalui personal chat whatsapp ataupun update status di whatsapp.

Tampilan tersebut dapat dilihat pada gambar 17 dan gambar 18 Menu share ini juga bisa share gambar objek wisata melalui pesan multimedia seperti yang terdapat pada gambar 19 .

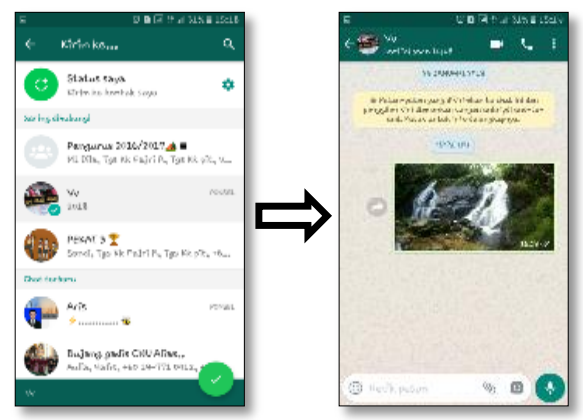

Gambar 17 Tampilan Share Gambar pada Personal Chat Whatsapp 


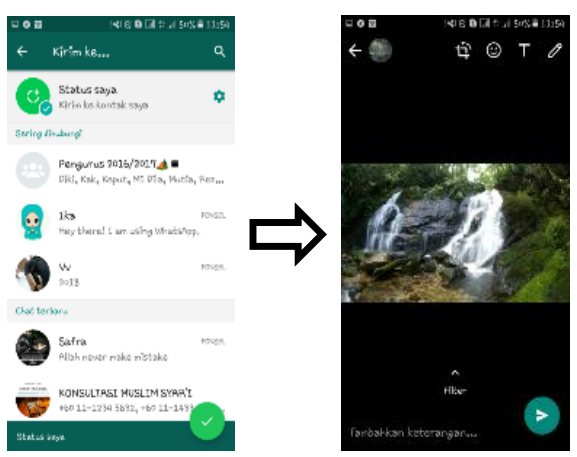

Gambar 18 Tampilan Share Gambar pada Pembaruan Status Whatsapp

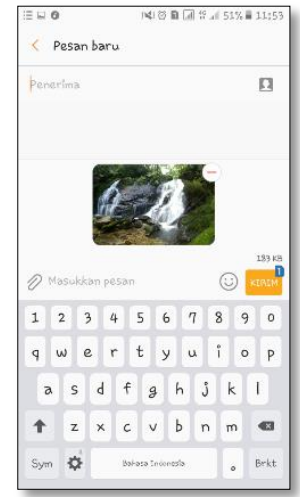

Gambar 19 Tampilan Share Gambar pada Pesan Multimedia

\section{Marker Peta Lokasi Objek Wisata}

Pada tampilan peta objek wisata terdapat marker. Marker ini berfungsi untuk penanda lokasi yang telah diinputkan oleh user melalui menu upload wisata, untuk menentukan posisi dimana terdapat sebuah objek wisata berada dengan mamasukkan latitude dan longitude, maka marker akan muncul di peta sesuai posisi yang telah diinputkan. Berikut adalah marker pada peta yang terdapat pada gambar 20 .

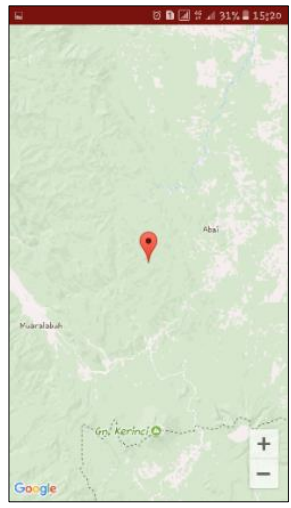

Gambar 20 Marker Peta Lokasi Objek Wisata

\section{Tampilan Informasi Marker}

Ketika marker di klik maka akan muncul kotak dialog yang berisi nama objek wisata. Berikut tampilan ketika klik marker pada gambar 21

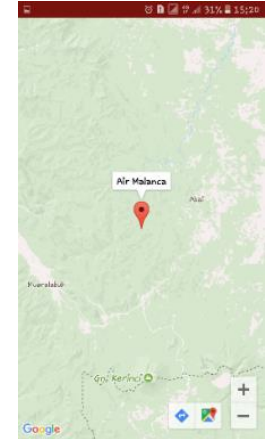

Gambar 21 Tampilan Informasi ketika Klik Marker

\section{Android Direction}

Untuk menampilkan petunjuk arah lokasi wisata dengan cara klik marker wisata dan pilih icon direction yang terdapat pada tampilan peta. Berikut tampilan user interface android direction pada gambar 22
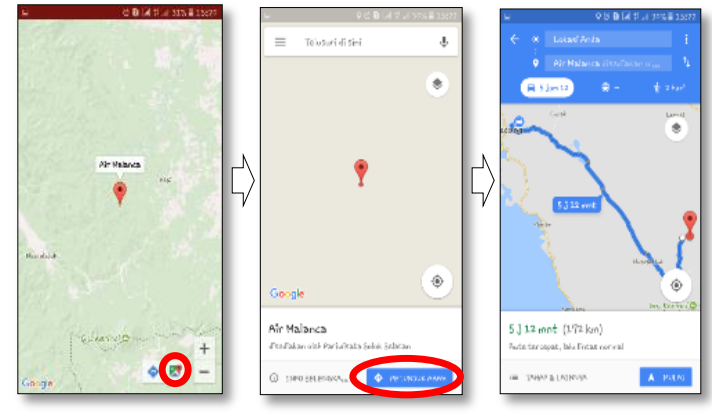

Gambar 22 Android Direction

\section{Android Rating}

User dapat memberikan penilaian terhadap objek wisata dengan cara rating. Penilaian rating hanya bisa dilakukan 1 kali pada objek wisata berdasarkan pembacaan ID telephone. Tampilan tersebut pada dilihat pada gambar 23 .

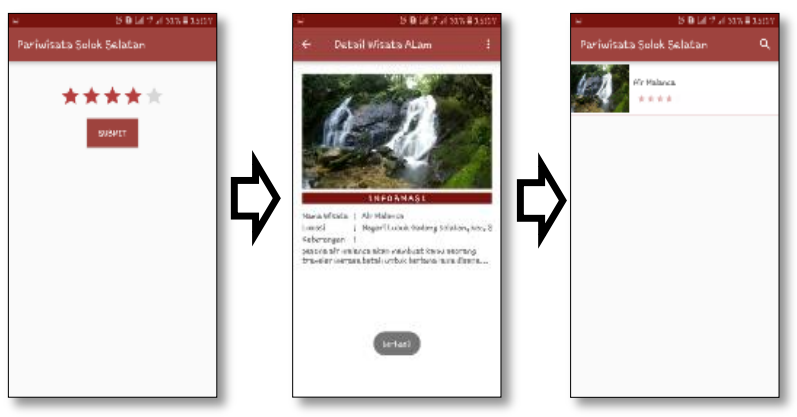

Gambar 23 Tampilan Pemberian Nilai Rating

Jika user belum menginputkan nilai rating maka muncul pesan seperti pada gambar 24. Apabila sudah melakukan penilain rating untuk satu objek wisata, maka tidak dapat melakukan rating yang kedua kalinya. Tampilan tersebut dapat dilihat pada Gambar 25$$
\text { Tampilan tersebut dapat dilihat pada Gambar } 25
$$

\author{
(5)
}


Vivi Hasti Mayanti, Hidra Amnur, Humaira, Dwiny Meidelfi Jurnal RESTI (Rekayasa Sistem dan Teknologi Informasi) Vol . 2 No. 3 (2018) 775 - 782

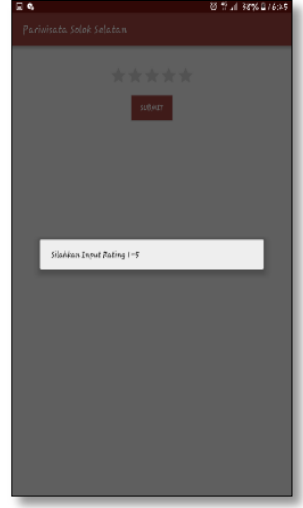

Gambar 24 Tampilan Pesan belum Melakukan Input Nilai Rating

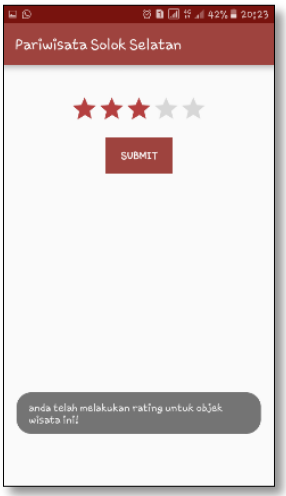

Gambar 25 Tampilan Pesan Penilaian Rating dengan Objek Wisata yang sama untuk yang Kedua kali

\section{Tentang Aplikasi}

Pada menu tentang aplikasi terdapat informasi mengenai mengenai aplikasi dan pembuat aplikasi. Berikut tampilan tentang aplikasi pada gambar 26.

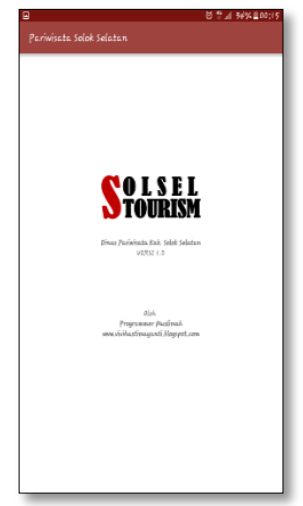

Gambar 26 Tentang Aplikasi

\section{Tentang Solok Selatan}

Pada menu tentang Solok Selatan terdapat informasi mengenai mengenai Solok Selatan secara umum. Berikut tampilan tentang Solok Selatan pada gambar 27.

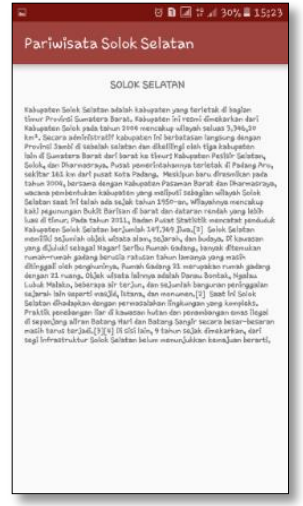

Gambar 27 Tentang Solok Selatan

\section{Menu Feedback}

Pada menu feedback, user dapat melaporkan apabila terjadi bug pada aplikasi dengan memilih Gmail dan pada halaman Gmail tercantum alamat email yang disediakan pembuat aplikasi agar mempermudah user dalam memberikan kritik dan saran. Berikut tampilan menu feedback yang terdapat pada gambar 28

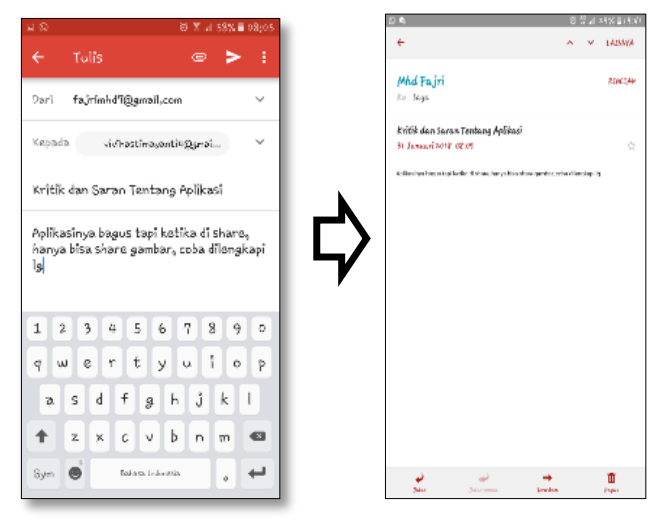

Gambar 28 Tampilan Menu feedback

\section{Menu Keluar}

Menu keluar berfungsi untuk keluar dari aplikasi seperti yang terdapat pada gambar 29.

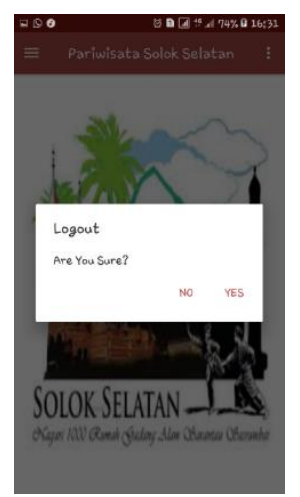

Gambar 29 Menu Keluar Aplikasi 


\section{Kesimpulan}

1. Aplikasi Pariwisata Solok Selatan berbasis android merupakan aplikasi yang memberikan informasi mengenai wisata yang di Kabupaten Solok Selatan. Bukan hanya memberikan informasi objek wisata tapi dengan aplikasi ini wisatawan ataupun pengguna aplikasi dapat mempublikasikan tempat wisata yang sudah dikunjungi ataupun tempat wisata yang belum pernah dijangkau wisatawan. Sehingga Pariwisata Kabupaten Solok Selatan dapat tereksposkan kembali.

2. Aplikasi Pariwisata Solok Selatan menggunakan maps dari Google Maps, untuk menampilkan maps tersebut membutuhkan API Key, API Key berfungsi untuk menampilkan Google Maps pada aplikasi.

3. Pengguna Aplikasi ini bisa share Objek Wisata berbentuk gambar ke berbagai media sosial atau aplikasi lainnya.

4. Pengguna aplikasi dapat memberikan penilaian terhadap objek wisata dengan penilaian rating.

\section{Daftar Rujukan}

[1] J. Andi, "Pembangunan Aplikasi Child Tracker berbasis Assisted-Global Positioning System (A-GPS) dengan Platform Android," Jurnal Ilmiah Komputer dan Informatika (KOMPUTA), vol. 1, no. 1, p. 3, 2015.

[2] "Undang-undang RI No 10 tahun 2009 tentang Kepariwisataan".

[3] N. Adi, Perancangan dan Implementasi Sistem Basis Data, Yogyakarta: ANDI, 2011.

[4] fathansyah, Basis Data, Bandung: Informatika, 2012.

[5] Hidra, Defni and A. Fatma, "Monitoring Kebocoran Pada Pipa Menggunakan SMS Gateway," Poli Rekayasa, vol. X, no. 2, p. $58,2015$.

[6] k. Peranginan, Aplikasi Web dengan PHP dan MySQL, Yogyakarta: ANDI, 2006.

[7] N. Adi, Rekayasa Perangkat Lunak Berorientasi Objek dengan Metode USDP, Yogyakarta: ANDI, 2010.

[8] S. Rizki, Android Dasar, 2013.

[9] S. H. Nazruddin, Android Pemrograman Aplikasi Mobile Smartphone dan Tablet PC Berbasis Android, Bandung: Informatika, 2014.

[10] M. Fahya and N. Fiftin, "PemanfataanGoogle Maps API Untuk Pembangunan Sistem Informasi Manajemen Bantuan Logistik Pasca Bencana Alam Berbasis Mobile WEB," Sarjana Teknik Informatika, vol. 1, no. 1, pp. 164-165, 2013. 